\title{
Are Genetic and Epigenetic Instabilities of Plant Embryogenic Cells a Fatality? The Experience of Coffee Somatic Embryogenesis
}

Hervé Etienne ${ }^{1 *}$, Benoît Bertrand ${ }^{1}$, Eveline Dechamp ${ }^{1}$, Patrick Maurel ${ }^{2}$, Frédéric Georget ${ }^{1}$, Romain Guyot $^{3}$ and Jean-Christophe Breitler ${ }^{1}$

${ }^{1}$ CIRAD, UMR IPME, 911 Avenue Agropolis, BP 64501, 34394 Montpellier, France

${ }^{2}$ Medesis Pharma SA, l'Orée des mas,Avenue du golf, 34670 Baillargues, France

IIRD, UMR IPME, 911 Avenue Agropolis, BP 64501, 34394 Montpellier, France

\begin{abstract}
In plants, undifferentiated or totally differentiated cells can be easily in vitro cultured to generate undifferentiated embryogenic cells that can regenerate complete plants. This is the most spectacular expression of totipotency. Embryogenic cells represent a key material in plant biotechnologies as they are used in many processes aiming at asexual reproduction by somatic embryogenesis (SE), genetic transformation, protoplast regeneration and cryopreservation. Nevertheless, tissue culture systems that involve the acquisition of competence for totipotency and extensive cell division remain risky with respect to genome and epigenome instabilities. Particularly, the use of embryogenic cell suspensions has frequently been associated with an increased likelihood of genetic instability and somaclonal variation (SV) in the regenerated plants. SV is a major concern in all in vitro vegetative plant propagation systems because it leads to the loss of genetic fidelity. Since 20 years, embryogenic cell suspension based SE techniques have been applied to coffee for the large-scale dissemination of exceptional Arabica hybrids. Here, we present our production and research experience showing that SE is efficient and reliable for true-to-type propagation. Over $99 \%$ of coffee trees regenerated fully conform to the mother plant, both morphologically - they grow, flower and produce normally. Hence strong genetic and epigenetic changes in proliferating embryogenic cells are not a fatality. The results also demonstrated the importance of embryogenic culture age on SV and hence the non-random nature of this phenomenon. The genetic and epigenetic alterations are particularly limited during SE. The main change in most of phenotypic variants was aneuploidy showing that mitotic aberrations play a major role in SV in coffee. These results provide a proof of concept for the use of embryogenic cell suspensions with other plant species: a revolution in the world of plant micropropagation on an industrial scale.
\end{abstract}

Keywords: Coffee somatic embryogenesis; Epigenetic; Fatality; Genetic; Plant embryogenic cells

Abbreviations: AFLP: Amplified Fragment Length Polymorphism; 6-BA: 6-benzylaminopurine; CIRAD: Centre International De Recherche En Agronomie Pour Le Développement, France; 2,4-D: 2,4-dichlorophenoxyacetic acid; iPSCs: Induced pluripotent stem cells; MSAP: Methylation-sensitive amplified polymorphism; SE: Somatic Embryogenesis; S-SAP: Sequence-Specific Amplification Polymorphism; SV: Somaclonal Variation; TEs: Transposable Elements.

\section{Introduction}

Although a large amount of coffee might be of great benefit for any person willing to read in one breath this entire volume of Human Genetics and Embryology, one might legitimately wonder why this paper on plant (coffee) embryogenic cells is published in this Journal. Shinya Yamanaka's group won the Nobel Prize for demonstrating the possibility to reprogram mouse somatic cells into induced pluripotent stem cells (iPSCs) in 2006 [1]. This procedure was initially based on retroviral transfection of four embryonic transcription factors in somatic cells and its was quickly followed by successful reprogramming of human somatic healthy $[2,3]$ and diseased $[4,5]$ cells. However, these strategies were hampered by modest reprogramming efficiency and safety issues. Numerous experimental approaches have been designed with the scope of improving these limitations using virus vector-free or transgene-free methods, modified mRNA strategy and small molecule treatments but, in spite of these worldwide efforts, the production of high generation efficiency and safety of iPSCs remains a challenge [6]. In sharp contrast with mammalian cells, plant somatic cells appear to be able to revert naturally/innately to the embryonic state and regenerate the whole plant both in vivo and more frequently in vitro. The case of coffee somatic embryogenesis is documented in this paper.

\section{Plant Embryogenic Cells: Obtaining, Potentialities and Risks for Their Use in Biotechnology}

Most somatic plant cells, whether undifferentiated meristematic cells or totally differentiated cells (e.g. stem, leaf, endosperm...), can regenerate into whole plants. Such a phenomenon, named totipotency first demonstrated by the pioneer works of Stewart and Reinert $[7,8]$ is based on the capacity for dedifferentiation: specialized cells can become again non specialized cells, and further differentiate again to regenerate all types of specialized cells. Cells belonging to fragments of competent organs are in vitro cultured to generate an undifferentiated mass of proliferating embryogenic cells called an embryogenic callus.

Embryogenic cells represent a key material in plant biotechnologies as they are used in many processes including asexual reproduction through somatic embryogenesis (SE), genetic transformation, protoplast regeneration and long-term cryopreservation in liquid nitrogen. In coffee, since the first achievement of embryogenic calli by Yasuda et al. [9], efficient and reliable technologies based on the use of embryogenic

*Corresponding author: Hervé Etienne, CIRAD, UMR IPME, 911 Avenue Agropolis, BP 64501, 34394 Montpellier, France, Tel: +33-467416227; E-mail: herve.etienne@cirad.fr

Received July 29, 2015; Accepted April 19, 2016; Published April 20, 2016

Citation: Etienne H, Bertrand B, Dechamp E, Maurel P, Georget F, et al. (2016) Are Genetic and Epigenetic Instabilities of Plant Embryogenic Cells a Fatality? The Experience of Coffee Somatic Embryogenesis. Human Genet Embryol 6: 136. doi:10.4172/2161-0436.1000136

Copyright: (C) 2016 Etienne $\mathrm{H}$, et al. This is an open-access article distributed under the terms of the Creative Commons Attribution License, which permits unrestricted use, distribution, and reproduction in any medium, provided the original author and source are credited. 
cells have been established in the two cultivated coffee species Coffea arabica and C. canephora, and are now available for research and breeding purposes [10-15]. Nevertheless, tissue culture systems that involve the acquisition of competence for totipotency and extensive cell division remain risky with respect to genome and epigenome stability [16]. Particularly, the use of embryogenic cell suspensions has frequently been associated with an increased likelihood of genetic instability and somaclonal variation (SV) in the regenerated plants [17-19]. SV is a major concern in all micropropagation systems. It is described as the phenotypic variation displayed in clonally propagated plants likely originated from a large array of genetic and epigenetic mechanisms [20]. The loss of genetic fidelity is detrimental for commercial purposes when the main objective is strictly the clonal propagation of elite plant material to ensure the maintenance of selected traits. Although embryogenic cell suspensions have been developed for some major crops, they have not been widely applied for commercial purposes. $\mathrm{SV}$ in embryogenic cell suspension-derived plants is probably related to the use of auxin (2,4-dichlorophenoxyacetic acid, 2,4-D), a plant hormone that is often essential for maintaining proliferating cells in an embryogenic undifferentiated state $[21,22]$.

\section{Somatic Embryogenesis for Mass Propagation of Coffee Elite Varieties}

In the 1990s Arabica F1 hybrids were obtained by CIRAD (Centre International de Recherche en Agronomie pour le Développement, France) and partners from crosses between cultivated American varieties and semi-wild trees originating from Ethiopia or Sudan. These hybrids led to $30 \%$ higher productivity in Central America, along with resistance to pests such as leaf rust and nematodes, whilst maintaining an excellent cup quality $[23,24]$. Because of the heterozygous character of the selected material, it was necessary to develop a vegetative propagation process allowing large-scale and rapid dissemination. SE has the best potential for rapid and large-scale multiplication of selected varieties in a wide range of economically important species. The challenge was particularly important because at that time the SE technology had only been applied at the industrial scale with oil palm, for which strong concerns with SV was observed [25].

Between 1995 and 2001, CIRAD moved the technique forward from a research laboratory scale to a technique enabling industrial dissemination of extremely promising Arabica F1 hybrids. Over that period, different technological innovations made technology transfer economically feasible: efficient multiplication of embryogenic cells and somatic embryo production in liquid medium in Erlenmeyer flasks, mass production of germinated embryos in temporary immersion bioreactors and the possibility of sowing them directly in the nursery. At the same time, reassuring data were obtained on the genetic conformity of regenerated plants (SV frequency $<3 \%$ ).

In 2002, in partnership with a private Cie (ECOM group), CIRAD decided to apply the SE method to four clones at the industrial scale. The SE process consisted of establishing embryogenic suspensions to favor large-scale embryogenic cell proliferation before the subsequent embryo differentiation step. In order to come up with an industrial procedure, the development of embryogenic cell suspension represents the best option to ensure synchronous and massive somatic embryo production [26]. In addition, embryogenic cell suspension allows the production of large numbers of embryogenic-competent cells and this process can be easily scaled up in bioreactors.

\section{Ensuring a True-To-Type In vitro Propagation}

With the objective of responding to a market evaluated to reach
20 million plants/year, controlling SV and propagation of individuals genetically identical to the mother plants were considered as a priority. A set of preventive measures was taken at the production level, in the production laboratory and in the nursery, to limit the appearance of variant trees. Preliminary studies on coffee $[27,28]$ previously showed that SV was systematically observed in all the regenerated plant batches and seven types of phenotypic variants were characterized (color of juvenile leaves, Giant, Dwarf, Thick leaf (Bullata), Variegata, Angustifolia, Multi-stem). For all genotypes, the degree of SV was low (1.3\%) for plants directly produced from embryogenic callus or 3-month-old embryogenic cell suspensions. Thereafter, the frequency of variants increased significantly, reaching 6,10 and $25 \%$ in plants produced from suspensions with ages of 6,9 and 12 months respectively.

It was also noted that the severity of SV increased with embryogenic suspension age and the 'Dwarf', 'Angustifolia' and 'multi-stem' phenotypic variants were successively represented. These observations led us to optimize the culture conditions for embryogenic cell suspensions in the framework of industrial production. Firstly, the multiplication time for suspended embryogenic cells was shortened to 6 months, since we previously showed that the frequency of variation is affected by that parameter. Likewise, multiplication was carried out in the presence of a reduced level of auxin $(2,4-D)$. Another precaution was the systematic plant assessment in the nursery, since some variants, such as 'Angustifolia' and 'Variegata', can be early detected and discarded.

In our experience, these variants only amount to $0.3 \%$ of total nursery production. The other phenotypic variants are only detected at the mature stage, one or two years after planting. Finally, the risk to get a high frequency of SV in a commercial batch is reduced by mixing regenerated plants from different cell lines at the end of the nursery phase. To ensure this objective, it was necessary to introduce a system of traceability of production batches derived from independent cell lines. In this way, commercial batches are constituted by a mix of several production batches (set of plants derived from the same in vitro culture initiation, themselves constituted by several embryogenic cell lines (set of plants derived from a same embryogenic callus). The maximal number of plants regenerated by an embryogenic coffee cell line is now fixed at 100,000 plants.

\section{Need for Up-Dated Information on Sv to Monitor Industrial Plant Micropropagation}

To date around 7 million somatic embryo-derived coffee plants are planted in Central American fields. As part of the rapid ongoing scaling-up of production, it appeared necessary to accurately evaluate the risks associated to SV and to discover the mechanisms leading to their occurrence. The objective was to guaranty to coffee growers trueto-type hybrid material and to that end, the development of in vitro and ex vitro procedures aimed at limiting the occurrence of SV, such as early molecular detection or efficient detection of variant plants at the nursery stage. Literature on SE frequently reports SV occurrence but few studies have been carried out on a large scale. Moreover, most of the time these studies are based on non-optimized in vitro culture protocols involving excessive concentrations of growth regulators. Regularly generating massive and accurate information on the SV impact in industrial conditions is important for an activity that is part of a sustainable scaling-up. Indeed as the risks associated with SV probably increase with scaling-up, even very full, robust information on the impact of SV at a scale cannot completely protect against an accident when working on a larger scale. With the aim to establish a safe and solid industrial process it was necessary to supplement massive studies with experiments to estimate the limits of the technology by 


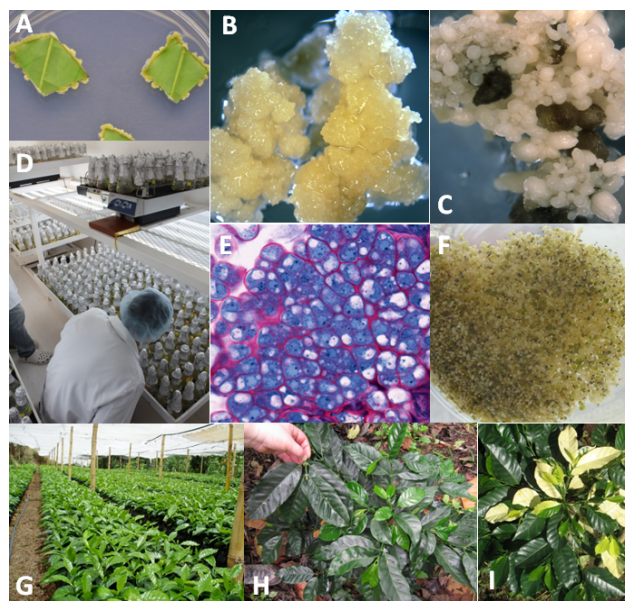

Figure 1: Illustration of the production, multiplication and plant regeneration from embryogenic cells in coffee (Coffea arabica). A) Formation of a primary callus constituted by meristematic cells at the edge of leaf explants 3 weeks following in vitro introduction; B) Embryogenic callus obtained 6 months after in vitro introduction; C) Somatic embryos regeneration from the embryogenic callus; D) Proliferation of embryogenic cell suspensions and subsequent somatic embryo regeneration in Erlenmeyer flasks agitated on orbital shakers in an industrial coffee micropropagation laboratory (CIRAD/ECOM unit, Sebaco, Nicaragua); E) Histological appearance of embryogenic cell clusters in suspension cultures; note that embryogenic cells exhibit a high nucleus cytoplasm ratio and dense cytoplasm rich in soluble and reserve proteins; F) Mass regeneration of torpedo-stage somatic embryos from embryogenic cell suspensions; G) Coffee somatic embryogenesis-derived plants in nursery (Cartago, Costa Rica); H) 'Dwarf' phenotypic variant (on the right) compared to a normal plant on the left; I) 'Variegata' phenotypic variant.

using culture conditions that are assumed mutagenic (long duration of cell proliferation in the presence of high growth regulators levels). In addition, these same experiments could also be important to identify the mechanisms leading to the SV.

\section{Recent Research Results on Genetic and Epigenetic Changes in Embryogenic Culture-Derived Plants}

The global objective of the research performed the last five years was to evaluate the true-to-type of SE derived plants, to understand better the mechanisms involved in SV and further optimize SE conditions, particularly the culture conditions of embryogenic cell suspensions. In a recent study [29], we assessed the variations in the propagated plants at the phenotypic, cytogenetic (chromosome counting), genetic [mutations/AFLP (amplified fragment length polymorphism), activation of transposable elements/S-SAP (sequencespecific amplification polymorphism retrotransposon-based molecular marker) and epigenetic (methylation/MSAP (methylation-sensitive amplified polymorphism)] levels by using two complementary approaches. First, we studied industrial culture conditions expected to be weakly mutagenic thanks to the combined use of short term proliferation period (6 months) and low auxin supply (0-1.4 $\mu \mathrm{M}$ 2,4-D). Two proliferation systems i.e. secondary embryogenesis and embryogenic cell suspensions were compared. AFLP and MSAP molecular analyses on 145 somatic seedlings showed that genetic and epigenetic polymorphisms between mother plants and somatic seedlings were extremely low, i.e. ranges of $0-0.003 \%$ and $0.07-0.18 \%$ respectively, with no significant difference between the proliferation systems. No plant was found to cumulate more than 3 methylation polymorphisms. Massive phenotypic observations in nursery and field plots showed very low levels of SV ( $0.9 \%$ from 800,000 plants).

In most coffee somaclonal variants, cytological analysis showed abnormal chromosome numbers $(41-43,45)$ compared with the normal number (44) in phenotypically normal plants. Stressful experimental conditions were also applied by using extended proliferation periods (4, 12 and 27 months) for three independent embryogenic cell lines established in the presence of high growth regulator concentrations (4.5 $\mu \mathrm{M}$ 2,4-D, $17.8 \mu \mathrm{M}$ 6-benzylaminopurine [6-BA]) to understand the mechanisms of culture ageing and their relations with SV [30]. The proliferation time strongly affected the SV frequency among the 180 regenerated plants and in a highly similar way with the three embryogenic cell lines. No variant was found after 4 months proliferation although $30 \%$ and $94 \%$ phenotypic variants were observed in plants derived from 12 and 27 month-old cultures, respectively. Regardless of the culture age and the embryogenic line, no polymorphisms were found in the 124 plants analyzed either with AFLP or with S-SAP using 13 different transposable elements from several families, and very limited polymorphisms were found in the methylation patterns using MSAP markers (0.049-0.087\%). However, similarly to plants derived from industrial conditions, phenotypic variants systematically showed abnormal chromosome numbers and normal plants systematically showed normal numbers (Figure 1).

\section{Conclusion}

This research showed that SE based on embryogenic cell suspensions is efficient and reliable for true-to-type propagation of selected C. arabica varieties. The results are clear: over $99 \%$ of coffee trees regenerated fully conform to the mother plant morphologically - they grow, flower and produce normally. Hence strong genetic and epigenetic changes in proliferating embryogenic cells are not a fatality. It also demonstrated that older embryogenic cultures are more susceptible to SV and hence the non-random nature of this phenomenon. The genetic and epigenetic alterations are particularly limited during SE. The main change in most of phenotypic variants was aneuploidy showing that mitotic aberrations play a major role in SV in coffee. These results open the way for the use of the embryogenic cell suspension technique to other plant species: a revolution in the world of plant micropropagation on an industrial scale. Research perspectives on somaclonal variation in coffee Although known to science since plant cell culture techniques were first developed, SV origins remain partly mysterious. In embryogenic coffee cells, the methylation polymorphism and transposable elements activity appeared very low, while chromosomal rearrangements are directly linked to SV. Beside chromosomal rearrangements we postulated that misregulation of small RNA pathways can make a significant contribution to the phenomenon [30]. 
MicroRNAs and related small RNAs appear ideal candidates because their mode of action gives them disproportionate influence over the transcriptome, proteome and epigenome. They regulate important developmental and physiological events such as meristem formation, phase changes, stress adaptation and hormone responses. However, the genomic of microRNA genes and their unique biogenesis might make them unusually susceptible to aberrant regulation in vitro [31]. The expression profiles of most miRNAs that are implicated in plant growth and development are significantly altered during stress [32].

Stress generated by in vitro culture could modify dramatically the cellular small RNAs content by at least three ways. Most plant stress responses are directly under the control of stress-responsive small RNAs. Furthermore, many small RNA genes reside in intergenic regions and some have been found nested in transposons. It suggests these genes can be far more susceptible to expression changes through altered DNA methylation and reorganization of local chromatin, which are typically observed in cultured cells. Finally, substantial variations in the expression levels of genes involved in microRNA processing and function, such as Dicer-like (DCL) or Argonaute (AGO) genes, can be observed under extreme tissue culture conditions which induce major changes in all the epigenetic pathways [33].

Further work is needed to clarify the responses of microRNA pathways to artificial culture systems. As more accurate and powerful tools for epigenetic analysis become available, analysis of the epigenetic landscape of plant cell cultures may turn out to be crucial for understanding variant phenotypes [16]. To determine whether microRNAs make significant contributions to generating SV during coffee tissue culture, genome and epigenome expression comparisons in two embryogenic cell lines cultured respectively 4 and 27 months need to be performed by whole mRNA and microRNA sequencing $[34,35]$.

By comparing these libraries, we will try to establish a link between cell culture ageing, epigenetic program destabilization and chromosomal rearrangements that are directly linked to SV in embryogenic coffee cells. A precise and comprehensive knowledge of the molecular basis of SV by correlating big genomic data with plant phenotype/behaviour in vitro would help to devise strategies to identify SE markers. In addition this knowledge could also improve the totipotency and embryogenic capability in recalcitrant species and genotypes, or long-lived species such as forest trees in which SV events may become noticed with mature individuals many years later.

\section{References}

1. Takahashi K, Yamanaka S (2006) Induction of pluripotent stem cells from mouse embryonic and adult fibroblast cultures by defined factors. Cell 126: 663-6.

2. Takahashi K, Tanabe K, Ohnuki M, Narita M, Ichisaka T, et al. (2007) Induction of pluripotent stem cells from adult human fibroblasts by defined factors. Cell 131: 861-72.

3. Yu J, Vodyanik MA, Smuga-Otto K, Antosiewicz-Bourget J, Frane JL, et al. (2007) Induced pluripotent stem cell lines derived from human somatic cells. Sci 318: 1917-20.

4. Dimos JT, Rodolfa KT, Niakan KK, Weisenthal LM, Mitsumoto H, et al. (2008) Induced pluripotent stem cells generated from patients with ALS can be differentiated into motor neurons. Sci 321: 1218-21.

5. Park IH, Arora N, Huo H, Maherali N, Ahfeldt T, et al. (2008) Disease- specific induced pluripotent stem cells. Cell 134: 877-86.

6. Ji P, Manupipatpong S, Xie N, Li Y (2016) Induced Pluripotent Stem Cells: Generation Strategy and Epigenetic Mystery behind Reprogramming. Stem Cells Int 11: 15-195R1.
7. Steward FC, Mapes MO, Mears K (1958) Growth and organized development of cultured cells. Il. Organization in cultures grown from freely suspended cells. American J Bot 45: 705-708.

8. Reinert J (1959) About the control of morphogenesis and the induction of adventitious to tissue cultures of carrot. Planta 53: 318-333.

9. Yasuda T, Fujii Y, Yamaguchi T (1985) Embryogenic callus induction from Coffea arabica leaf explants by benzyladenine. Plant Cell Physiol 26: 595-597.

10. Acuna JR, de Pena M (1991) Plant regeneration from protoplasts of embryogenic cell suspensions of Coffea arabica L. cv. Caturra. Plant Cell Rep 10: $345-348$.

11. Etienne-Barry D, Bertrand B, Vasquez N, Etienne H (1999) Direct sowing of Coffea arabica somatic embryos mass-produced in a bioreactor and regeneration of plants. Plant Cell Rep 19: 111-117.

12. Hatanaka T, Choi YE, Kusano T, Sano H (1999) Transgenic plants of coffee Coffea canephora from embryogenic callus via Agrobacterium tumefaciens mediated transformation. Plant Cell Rep 19: 106-110.

13. Ducos JP, Lambot C, Pétiard V (2007) Bioreactors for coffee mass propagation by somatic embryogenesis. Int J Plant Dev Biol 1: 1-12.

14. Ribas A, Dechamp E, Bertrand B, Champion A, Verdeil JL, et al. (2011) Agrobacterium tumefaciens-mediated genetic transformation of Coffea arabica (L.) is highly enhanced by using long-term maintained embryogenic callus BMC Plant Biol 11: 92.

15. Etienne H, Bertrand B, Montagnon C, Bobadilla Landey R, Dechamp E, et al (2012) An example of successful technology transfer in micropropagation: the multiplication of Coffea arabica by somatic embryogenesis. Cah Agri 21: 11524.

16. Miguel C, Marum L (2011) An epigenetic view of plant cells cultured in vitro: somaclonal variation and beyond. J Exp Bot 62: 3713-3725.

17. Jähne A, Lazzeri PA, Jäger Gussen M, Lörz H (1991) Plant regeneration from embryogenic cell suspensions derived from anther cultures of barley (Hordeum vulgare L.). Theor Appl Genet 82: 74-80.

18. Rival A, Beulé T, Barre P, Hamon S, Duval Y, et al. (1997) Comparative flow cytometric estimation of nuclear DNA content in oil palm (Elaeis guineensis Jacq.) tissue cultures and seed-derived plants. Plant Cell Rep 16: 884-887.

19. Lu S, Wang Z, Peng X, Guo Z, Zhang G, et al. (2006) An efficient callus suspension culture system for triploid bermudagrass (Cynodon transvaalensis x C. dactylon) and somaclonal variations. Plant Cell Tiss Org Cult 87: 77-84.

20. Neelakandan AK, Wang K (2012) Recent progress in the understanding of tissue culture-induced genome level changes in plants and potential applications. Plant Cell Rep. 31: 597-620.

21. Lambé P, Mutambel HSN, Fouche JG, Deltour R, Foidart JM, et al. (1997) DNA methylation as a key process in regulation of organogenic totipotency and plant neoplastic progression. In Vitro Cell Dev Biol Plant 33: 155-162.

22. Von Aderkas $P$, Bonga $J$ (2000) Influencing micropropagation and somatic embryogenesis in mature trees by manipulation of phase change, stress and culture environment. Tree Physiol 20: 921-928.

23. Bertrand B, Etienne $H$, Cilas C, Charrier A, Baradat $P$ (2005) Coffea arabica hybrid performance for yield, fertility and bean weight. Euphytica 141: 255-262.

24. Bertrand B, Alpizar E, Llara L, Santacreo R, Hidalgo M, et al. (2011) Performance of Arabica F1 hybrids in agroforestry and full-sun cropping systems in comparison with pure lines varieties. Euphytica 181: 147-158.

25. Morcillo F, Gagneur C, Adam H, Richaud F, Singh R, et al. (2006) Somaclonal variation in micropropagated oil palm. Characterization of two novel genes with enhanced expression in epigenetically abnormal cell lines and in response to auxin. Tree Physiology 26: 585-594.

26. Etienne H, Dechamp E, Barry-Etienne D, Bertrand B (2006) Bioreactors in coffee micropropagation (Review). Brazilian J Plant Physiol 18: 45-54.

27. Etienne H, Bertrand B (2001) The effect of the embryogenic cell suspension micropropagation technique on the trueness to type, field performance, bean biochemical content and cup quality of Coffea arabica trees. Tree physiol 21 1031-1038.

28. Etienne H, Bertrand B (2003) Somaclonal variation in Coffea arabica : effects of genotype and embryogenic cell suspension age on frequency and phenotype of variants. Tree Physiol 23: 419-426. 
Citation: Etienne H, Bertrand B, Dechamp E, Maurel P, Georget F, et al. (2016) Are Genetic and Epigenetic Instabilities of Plant Embryogenic Cells a Fatality? The Experience of Coffee Somatic Embryogenesis. Human Genet Embryol 6: 136. doi:10.4172/2161-0436.1000136

29. Bobadilla Landey R, Cenci A, Georget F, Bertrand B, Camayo G, et al. (2013) High genetic and epigenetic stability in Coffea arabica plants derived from embryogenic suspensions and secondary embryogenesis as revealed by AFLP, MSAP and the phenotypic variation rate. PloS ONE 8: e56372.

30. http://www.plosone.org/article/info\%3Adoi\%2F10.1371\%2Fjournal. pone.0056372

31. Bobadilla Landey R, Cenci A, Bertrand B, Georget F, Dechamp E, et al. (2015) Assessment of genetic and epigenetic changes during cell culture ageing in coffee and relations with somaclonal variation. Plant Cell Tiss Org Cult 3: 517-531.

32. Mahdavi-Darvari F, Mohd Noor N, Ismanizan I (2015) Epigenetic regulation and gene markers as signals of early somatic embryogenesis. Plant Cell Tiss Org Cult 120: 407-422.

33. Sunkar R, Li YF, Jagadeeswaran G (2012) Functions of microRNAs in plant stress responses. Trends in Plant Science 17: 196-203.

34. Rodriguez-Enriquez J, Dickinson HG, Grant-Downton RT (2011) MicroRNA misregulation: an overlooked factor generating somaclonal variation? Trends in Plant Science 16: 242-248.

35. Tanurdzic M, Vaughn MW, Jiang H, Lee TJ, Slotkin RK, et al. (2008) Epigenomic consequences of immortalized plant cell suspension culture. PLoS Biol 6 : 2880-2895. 